\title{
0 DIREITO FUNDAMENTAL AO MEIO AMBIENTE NO CONTEXTO IBERO-AMERICANO: BRASIL E ESPANHA
}

ÉmILIEN VILAS BOAS ReIS

Graduado em Filosofia (UFMG), mestre e doutor em Filosofia (PUC-RS). Pósdoutor em filosofia (FLUP-Porto). Professor de Filosofia e Filosofia do Direito do programa de graduação e pós-graduação em Direito da Escola Superior Dom Helder Câmara (BH). Coordenador do Grupo de Pesquisa "Pensar a cidade: seus aspectos ambientais, jurídicos e sociais".

MARIZA Rios

Graduada em Direito pela Universidade Gama Filho do Rio de Janeiro. Especialista em Direto Público pela Faculdade de Direito do Vale do Rio Doce. Mestra em Direito, Estado e Constituição pela UnB - Universidade Nacional de Brasília, com pesquisa na Universidade de Coimbra sob a orientação de Boaventura de Souza Santos. Professora na Escola Superior Dom Helder Câmara. Doutoranda em Direito na Universidade Complutense de Madrid, Espanha. Membro do Grupo de Pesquisa "Pensar a cidade: seus aspectos ambientais, jurídicos e sociais".

\section{Resumo}

Inicialmente, o artigo debate o meio ambiente como direito fundamental, a partir de documentos históricos e análises jurídicas e filosóficas. Em seguida, debruça-se sobre o direito fundamental ao meio ambiente no contexto ibero-americano, especificamente, o Brasil e a Espanha. Num terceiro momento, o artigo caracteriza a democracia, a partir de Jürgen Habermas, como o regime que permite a convivência de diferentes discursos e a participação ativa da sociedade, o que possibilita a construção do direito fundamental ao meio ambiente, o cuidado com o ambiente e sua relação com a vida digna garantida pela Constituição.

\section{Palavras-chave}

Meio ambiente; Direito fundamental; Democracia; Participaçáo.

\section{Abstract}

Initially, this paper discusses the environment as a fundamental right, based on historical documents and legal and philosophical analysis. Then focuses on the fundamental 
right to environment in Ibero-American context, more specifically with Brazil and Spain. Thirdly, this paper characterizes democracy as of Jürgen Habermas, as the regime which allows the coexistence of different discourses and the active participation of society, which allows the construction of the fundamental right to environment, the care for the environment and its relationship with the dignified life guaranteed by the Constitution.

\section{Key words}

Environment; Fundamental rights; Democracy; Participation.

\section{Introdução}

O foco do presente ensaio é pensar o meio ambiente urbano no conjunto dos direitos fundamentais protegidos pela Constituição do Estado, no contexto ibero-americano, nomeadamente, Brasil e Espanha, e, portanto, no rol dos direitos constitutivos dos pilares da Democracia. Tal enfoque chama a atenção para o resgate do princípio da participação social como condição importante no reconhecimento, na promoção e no respeito ao meio ambiente urbano.

Para tanto, em primeiro lugar, debruçamo-nos sobre o resgate conceitual a partir do olhar filosófico, entendendo o meio ambiente como direito fundamental historicamente ameaçado. Em segundo lugar, analisamos o contexto atual com foco nos instrumentos jurídicos de proteção ao direito fundamental ao meio ambiente tendo o princípio da participação social um lugar de destaque no reconhecimento, cuidado, proteçáo e promoção do direito fundamental ao meio ambiente.

Por fim, o texto faz uma leitura conectiva entre direitos humanos, direitos fundamentais e democracia, a partir de Habermas, com o fim de apontar a necessidade do reconhecimento e do exercício da participação democrática como princípio basilar na concretização da proteção e da promoção de iniciativas públicas em favor do meio ambiente adequado.

\section{Direitos Humanos e Meio Ambiente: Uma Relação Necessária}

Em um diálogo ocorrido há mais de dois mil anos, duas importantes figuras da antiguidade grega, o médico Hipócrates, e o filósofo pré-socrático Demócrito, mantêm uma conversa que toca na questão do que seria uma vida digna de ser vivida. A partir de uma genial intuição, o filósofo, muito antes da existência do modo exponencial destrutivo de vida contemporâneo, afirma que:

Pero yo sólo me río del hombre, lleno de estupidez, desprovisto de acciones rectas, [...] que con ansias desmesuradas recorre la tierra hasta sus 
confines y penetra en sus inmensas cavidades, funde el oro y la plata, lo acumula sin descanso y esfuerza por poseer cada vez más para ser cada vez menos. No se avergüenza de llamarse feliz porque excava las profundidades de la tierra por medio de hombres encadenados: entre ellos, algunos mueren a causa de los derrumbes de tierra; otros, sometidos a una larguíssima esclavitud, viven en esta prisión como en su patria. Buscan oro y plata, hurgando entre polvo y desechos, desplazan montones de arena, abren las venas de la tierra para enriquecerse, despedazan la madre tierra. (HIPÓCRATES apud ORDINE, 2013, p. 112) [grifos no original]

Demócrito, dirigindo-se a Hipócrates, afirma que não é feliz aquele que apenas extrai das profundezas do chão, despedaçando a "mãe-terra". A fala do grego ilustra que a dignidade humana depende do cuidado que se tem com a natureza, aqui entendida também como meio ambiente urbano. Na verdade, pode-se perceber como a preocupação ambiental é uma forma de garantir uma vida digna de ser vivida.

Nesse sentido, o texto que se segue defende a tese de que a dignidade humana só se concretiza com as garantias ambientais - incluindo o meio ambiente urbano - que dependem fundamentalmente dos aparatos jurídicos para se consolidarem, pautadas, sempre, em uma ética como fundamento.

Direitos humanos são entendidos como aqueles intrínsecos às pessoas humanas, protegidos pelas constituiçóes e ilustrados por muitos documentos internacionais, tais como a Declaração Universal dos Direitos Humanos, criada em 1948 pela Assembleia Geral das Naçóes Unidas (ONU) com a finalidade de resguardar o ser humano contra atos que póem em risco a sobrevivência de toda a humanidade. No início da Declaraçáo encontra-se:

Considerando que o desprezo e o desrespeito pelos direitos humanos resultaram em atos bárbaros que ultrajaram a consciência da Humanidade e que o advento de um mundo em que todos gozem de liberdade de palavra, de crença e da liberdade de viverem a salvo do temor e da necessidade foi proclamado como a mais alta aspiraçáo do homem comum, [...].

A Assembleia Geral proclama a presente Declaração Universal dos Direitos Humanos como o ideal comum a ser atingido por todos os povos e todas as naçôes [...]. (DECLARAÇÃO UNIVERSAL DOS DIREITOS HUMANOS, 1948)

Uma das grandes dificuldades na contemporaneidade é a defesa e a sistematização dos direitos humanos. De acordo com Kaufmann:

Esses direitos, em primeiro lugar, pertencem ao homem enquanto homem, sem nenhuma outra qualificação, e, de fato, a todo homem independentemente de sexo, cor de pele, raça e posição social, em segundo lugar, eles não podem ser arbitrariamente descartados, sendo antes 
inalienáveis. Possuímos tais direitos porque somos homens, e enquanto formos homens. Qualquer contrato por meio do qual alguém venha a abdicar de sua vida ou de sua liberdade já está invalidado de antemão. (KAUFMANN, 2013, p. 46)

Os direitos humanos podem ser entendidos como direitos inerentes à natureza humana e que emanam do princípio da dignidade da pessoa humana.

Quando se fala de dignidade humana, entende-se uma dignidade que inere ao homem, que lhe é concedida independentemente de outro qualificativo, seja biológico, social ou moral. Desse modo, ela se distingue das diversas formas de dignidade contingente. Fala-se, por exemplo, de dignidade social em relação aos portadores de cargos políticos ou clericais; de dignidade expressiva, quando a aura de um homem sábio infunde reverência; por outro lado, fala-se da conduta indigna de um bêbado qualquer. A dignidade humana, ao contrário, consiste num conceito normativo, que deve proteger todo homem de ser tratado como meio, isto é, como um simples objeto para a consecuçáo de seus fins. Isso implica que todos sejam tratados como possuidores de certo grau de dignidade contingente, o que é uma tentativa de proteger os homens de humilhações. (KAUFMANN, 2013, p. 55) [grifos no original]

Posto isso, devemos nos voltar para as questôes ambientais e suas relaçóes com os direitos humanos. A Declaração de Estocolmo sobre o Ambiente Humano de 1972 originou-se do diálogo entre as naçóes, com o intuito de lidar com os temas pautados na tutela ambiental. Em seu Princípio 1 já se encontra a consideração de que o meio ambiente é um direito humano:

O homem tem o direito fundamental à liberdade, à igualdade e ao desfrute de condiçôes de vida adequadas em um meio ambiente de qualidade tal que lhe permita levar uma vida digna e gozar de bem-estar, tendo a solene obrigação de proteger e melhorar o meio ambiente para as geraçóes presentes e futuras. [...]. (DECLARAÇÃO DE ESTOCOLMO SOBRE O AMBIENTE HUMANO, 1972)

$\mathrm{Na}$ evolução dos direitos humanos, o meio ambiente foi compreendido por alguns como sendo direitos de terceira geração. A proteção à natureza pode ser encarada como uma maneira de assegurar a realização dos direitos humanos, pois, no momento em que acontece um estrago no ambiente, também ocorre a violação aos demais direitos fundamentais, tais como a vida, a liberdade e a proteção física.

$\mathrm{Na}$ medida em que o direito a um ambiente digno e sadio passou a ser considerado um direito humano de terceira geração, transgredi-lo é também uma infração aos direitos humanos. A citada Declaração de Estocolmo (1972) proclama de maneira explícita em seu item 1, a preocupação com o meio ambiente e com o ser humano ao mesmo tempo: 
1. O homem é, a um tempo, resultado e artífice do meio que o circunda, o qual lhe dá o sustento material e o brinda com a oportunidade de desenvolver-se intelectual, moral, social e espiritualmente. Na longa e tortuosa evoluçáo da raça humana neste planeta chegou-se a uma etapa na qual, em virtude de uma rápida aceleração da ciência e da tecnologia, o homem adquiriu o poder de transformar, por inúmeras maneiras e numa escala sem precedentes, tudo quanto o rodeia. Os dois aspectos do meio humano, o natural e o artificial, são essenciais para o bem-estar do homem e para que ele goze de todos os direitos humanos fundamentais, inclusive o direito à vida. (DECLARAÇÃO DE ESTOCOLMO SOBRE O AMBIENTE HUMANO, 1972)

A efetivação do meio ambiente como um direito humano fundamental torna-se necessária, pois estão fundamentalmente interligados. Sua realização significa a preservação e a melhora da qualidade de vida. A dignidade da pessoa humana, vista como direito fundamental absoluto, garantido a todos da espécie humana, tem como objetivo proporcionar uma vida digna a todos os povos. Mas a dignidade só se efetiva se o ser humano tem todos os direitos fundamentais cobertos. Se o direito a um meio ambiente ecologicamente equilibrado é transgredido, também é infringida a dignidade da pessoa humana.

Assim, todas as Naçôes, por meio de participação em todas as instâncias sociais, a partir de noçốes como solidariedade e equidade, devem unir esforços para manter o meio ambiente saudável e digno, para que todos os povos, de qualquer classe econômica e social, incluindo as futuras geraçôes, fiquem resguardados.

O humanista e jurista francês René Cassin, que estava presente e contribuiu para a elaboração da Declaração Universal dos Direitos Humanos, afirma que nesta declaração "a comunidade internacional reconheceu que o indivíduo é membro direto da sociedade humana, na condição de sujeito direto dos Direitos das Gentes. Naturalmente, é cidadão de seu país, mas também é cidadão do mundo" (CASSIN apud PIOVESAN, 2008, p. 136). Para Cassin, a Declaração se caracteriza por: a) sua amplidão, que abrange um conjunto de direitos e faculdades sem as quais um ser humano não pode desenvolver sua personalidade física, moral e intelectual; b) sua universalidade, pois abrange as pessoas de todos os países, raças, religióes e sexos, independentemente do regime político em que se encontram.

A relação entre meio ambiente e direitos humanos pode ser vista atualmente como inevitável. Sem a existência de uma natureza ecologicamente equilibrada, é impossível viver efetivamente os direitos expostos na Declaraçáo Universal dos Direitos Humanos. Kambumba ilustra tal visão com alguns interessantes exemplos:

De que serviria a liberdade de um indivíduo que, para aplacar sua sede, é obrigado a consumir água poluída por dejetos tóxicos, que está condenado a sofrer durante toda sua vida de um câncer causado pela poluição 
atmosférica ou que se vê impelido a emigrar de seu país para viver em condiçôes precárias, porque este foi o único recurso para evitar os efeitos da desertificação? (KAMBUMBA apud CARVALHO, Edson, 2011, p. 95)

No Brasil, a dignidade da pessoa humana foi consagrada no inciso III, do artigo $1^{\mathrm{o}}$ da Constituição de 1988:

Art. $1^{\circ}$ A República Federativa do Brasil, formada pela união indissolúvel dos Estados e Municípios e do Distrito Federal, constitui-se em Estado Democrático de Direito e tem como fundamentos:

$[\ldots]$

III - a dignidade da pessoa humana.

No momento em que os direitos humanos são colocados em um texto constitucional, são considerados direitos fundamentais. Nas palavras de Pereira:

Do ponto de vista formal, direitos fundamentais são aqueles que a ordem constitucional qualifica expressamente como tais. Já do ponto de vista material, são direitos fundamentais aqueles direitos que ostentam maior importância, ou seja, os direitos que devem ser reconhecidos por qualquer Constituição legítima. (PEREIRA, 2006, p. 77)

Dessa forma, deve-se fundamentar a noção de que o direito ao meio ambiente ecologicamente equilibrado é um direito humano fundamental, derivando do princípio absoluto da dignidade da pessoa humana, que se encontra nos chamados direitos de terceira geração.

$\mathrm{O}$ direito ao meio ambiente, que se diferencia de um direito individual, consiste num direito-dever, no sentido de que o Estado, ao mesmo tempo que o titulariza, deve preservá-lo e defendê-lo, em níveis procedimentais e judiciais, consubstanciando-se uma verdadeira noção de solidariedade em torno do bem comum.

Nesse viés, enfatiza-se mais uma vez que os direitos humanos e o direito a um meio ambiente sadio e equilibrado estão constitucionalmente protegidos e interligados, pois almejam a preservação da vida e procuram garantir a sobrevivência dos seres humanos e do planeta e, portanto, constitui um direito fundamental. Não podem ser vistos separadamente, já que a transgressão de um deles provoca múltiplos desequilíbrios ambientais, trazendo consequências, às vezes irreversíveis, que colocam em risco a existência da espécie humana e dos recursos naturais necessários para a manutenção vital do planeta:

O Direito Ambiental é em si reformulador, modificador, pois atinge toda a organização da sociedade atual, cuja trajetória conduziu à ameaça da existência humana pela atividade do próprio homem, o que jamais ocorreu em toda história da humanidade. Um Direito que surge para rever e 
redimensionar conceitos que dispóem sobre a convivência das atividades sociais bem como para resolver problemas inter-relacionados de proteção ambiental, permeando praticamente todo o conjunto da ordem jurídica, superando, com isto, toda a classificação tradicional sistemática do Direito. (DERANI, 1997, p. 75)

O ideal para as relaçóes sociais seria que os homens se preocupassem uns com os outros, sem a necessidade de intervenção exterior. Infelizmente, não é isso que vem ocorrendo ao longo do processo civilizatório. Por mais que se declame um discurso sobre o cuidado com a natureza e com o outro, a atuação do Direito é fundamental para a garantia de um meio ambiente ecologicamente equilibrado. A conscientização a respeito da natureza é algo que pode ser implantado com educação e costumes, mas as questóes ambientais são urgentes e, por isso, dependem também da intervenção jurídica. Entretanto, isso não significa uma defesa simples de positivismos legais.

Hegel, um dos precursores do pensamento contemporâneo, chamava a atenção para a necessidade de o Estado garantir o cumprimento do que se pressupóe ético. Para Hegel, Kant decretou a separação entre as instâncias éticas e políticas, diferentemente dos gregos. O filósofo propóe a relação intrínseca entre as instâncias éticas e políticas. Veja-se o que diz Herrero a esse respeito:

Hegel, pelo contrário, na sua tentativa de recuperar a dimensão da eticidade grega nas condiçóes da moralidade kantiana, insistirá em que a liberdade subjetiva do indivíduo e sua moralidade só podem se desenvolver e realizar no interior de um Estado formado por instituiçóes sociais e políticas que correspondam à natureza desse indivíduo moral e livre e, onde, por sua vez, as instituiçôes sociais e políticas só poderão sustentar-se sobre o fundamento de indivíduos que estejam verdadeiramente dispostos a viver a moralidade. Dito kantianamente: moralidade que não possa realizar-se objetivamente, externamente, na vida social e política, é como um sopro sem substância. Instituiçôes sociais e políticas que não tenham sua realidade nos indivíduos, dispostos a viver sua verdadeira liberdade, são como carcaças vazias. O verdadeiro Estado só poderá sustentar-se, não pelo poder, pela força e coerção externa, mas pela identificação dos indivíduos com suas instituiçôes sociais e políticas. (HERRERO, 2004, p. 153)

Hegel vislumbrou a perfeita sintonia entre a dimensão política e ética inicialmente na Revolução Francesa, mas logo mudou de opinião sobre tal evento histórico. Por mais que seja difícil conciliar essas dimensóes, tal visão pode se tornar um norte para as realizaçóes humanas.

Mesmo que o meio ambiente, em escala global, continue sendo negligenciado em muitos aspectos, é extremamente importante que vários documentos internacionais e as 
diferentes legislaçóes, inclusive a brasileira, garantam a preservação ambiental, por meio dos seus instrumentos legais. Junto a isso, é importante que uma ética ambiental sirva de fundamento para as relaçôes sociais. A relação intrínseca entre os dois níveis pode evitar a arbitrariedade e a violência que muitas vezes a lei positiva gera, quando pautada em interesses escusos.

Também sendo contra a separação kantiana entre moral e direito, Lima Vaz, referido por Mac Dowell pensa que:

[...] o legislador, como quer Kant, não pode exigir que a ideia do dever seja o motivo da ação. Basta-lhe que a ordem que impõe a ação exterior seja obedecida. Nem por isso, a lei, como forma da ação justa, deixa de ter um caráter essencialmente ético. Sendo, com efeito, a ação justa um ato da virtude da justiça, a definição, aplicação e cumprimento da lei e o exercício do Direito devem estar compreendidos no âmbito da justiça, não só como regra, mas, sobretudo, como virtude naquele que administra o Direito e naquele que tem o dever de respeitá-lo. A separação moderna entre Ética e Direito resulta, convém repetir, do abandono da teleologia do bem, em geral, e do bem comum na compreensão da comunidade política, pela inversão da primazia do ser e do bem, própria da Ética clássica, em favor do primado do sujeito e do útil. Daí se segue o desaparecimento da perspectiva da justiça como virtude, i.e. como perfeição imanente ao sujeito na sua relação com o outro, que dá lugar à primazia dos interesses individuais sobre a comunidade ética e, por conseguinte, à hipertrofia da justiça legal e a um legalismo abstrato e muitas vezes injusto. (LIMA VAZ apud MAC DOWELL, 2007, p. 266-267) [grifos no original]

Os direitos humanos, incluindo um meio ambiente ecologicamente equilibrado, fazem a ligação entre direito e ética. Assim, o Direito Ambiental existe como garantidor da dignidade humana. Os princípios que norteiam os valores fundamentais da humanidade são garantidos a partir de um meio ambiente sadio.

A preocupação ambiental ilustra, na prática, uma abertura para o outro, seja o indivíduo vivo e aquele que ainda não veio a ser, os demais seres vivos, os seres não vivos, o planeta. É por isso que o conceito de dignidade está implicado na reflexão sobre o direito ambiental. Nos dizeres de Ricardo Timm:

O Outro é a condição da socialidade real, aquela que não é uma mera multiplicação de indivíduos e grupos, que é qualidade e não mera quantidade, que é conteúdo e náo mera forma, e que pode reduzir as falsas sociabilidades, as sociedades falsas, baseadas na exploração do Outro e da natureza, à sua crua essência perversa, mostrando-as como, simplesmente, a disseminação da Totalidade que se disfarça interminavelmente em conceitos caros à tradição e que se transmuta a cada instante naquilo que o delírio quer ouvir: a paralisia do tempo e do espaço em torno ao pólo 
único de sentido, a mônada solitária. Quebrar a lógica do sentido único, trincar irrevogavelmente a mônada solitária, é a condição da dignidade humana. (TIMM, 2008, p. 147)

\section{0 Direito Fundamental ao Meio Ambiente}

Uma leitura histórica do Estado Moderno, em termos constitucionais, leva-nos a perceber que sua consolidação ocorreu ao longo de século XIX, sob a forma de Estado de Direito. Nos países da Europa, consolidou-se, em sua grande maioria, o modelo monárquico constitucional e na América Latina, tem-se o federalismo como escolha predominante, nomeadamente, o Brasil.

Aponta Barroso que, sendo federalista ou monárquico, o núcleo fundante centrouse nas normas de repartição, limitação de poder e proteção dos direitos fundamentais em face do Estado. No século XX foi que se aprofundou a questão da importância da legitimação do poder e da representação política na qual as questóes que ocuparam centralidade foram, por exemplo, a fonte do poder, a maneira como se toma decisóes e o que deve ou não ser decidido, ou seja: a fonte, o procedimento e o conteúdo da obrigação de fazer e de não fazer do Estado. Por essa razão, a consolidação do Estado Democrático de Direito vai ocorrer já no século XX.

Nesse contexto, afirma Barroso:

Quanto ao Estado de Direito, é certo que, em sentido formal, é possível afirmar sua vigência pela simples existência de algum tipo de ordem legal cujos preceitos materiais e procedimentais sejam observados tanto pelos órgãos de poder quanto pelos particulares. (BARROSO, 2015, p. 65)

Prosseguindo em sua doutrina, o autor fala sobre Democracia, indicando:

Já no tocante à democracia, é possível considerá-la em uma dimensão predominantemente formal, que inclui a ideia de governo da maioria e de respeito aos direitos individuais. [...] A Democracia em sentido material, contudo, que dá alma ao Estado constitucional de direito, é mais do que governo da maioria, o governo para todos. Isso inclui náo apenas as minorias - raciais, religiosas, culturais -, mas também os grupos de menor expressão política, ainda que não minoritários como as mulheres e, em muitos países, os pobres em geral. (BARROSO, 2015, p. 65)

A realização da Democracia requer, portanto, segundo o mesmo autor, o alargamento da obrigação positiva do Estado na promoção dos direitos sociais em um patamar mínimo de segurança da dignidade humana (BARROSO, 2015). Dignidade aqui entendida como princípio norteador dos princípios constitucionais o que já fora reconhecido 
por Canotilho (2003) como princípio dos princípios onde a centralidade da vida digna ocupa a primazia.

Após essas considerações, trataremos de pensar o meio ambiente como direito fundamental constitucional especialmente no contexto das Constituiçóes brasileira e espanhola.

\subsection{A Constituição e o Direito Fundamental ao Meio Ambiente}

No cenário moderno, segundo José Afonso da Silva (2015), o direito ao meio ambiente passa a ocupar centralidade constitucional fazendo parte do bloco de direitos fundamentais que tem a solidariedade como centralidade e, assim, considerados novos direitos que foram paulatinamente integrados aos direitos fundamentais difusos no horizonte constitucional.

E, nesse sentido, o mesmo autor, citando Pontes de Miranda (1993), justifica que a presença desses novos direitos no contexto constitucional se deve a transformaçóes social, econômica e cultural, ocorridas antes de serem incorporados à Constituição brasileira. $\mathrm{Ou}$ seja, foram as transformaçóes citadas que apontaram para a necessidade de reconhecimento de novos direitos, inclusive o debatido em tela - meio ambiente -, em um processo que pode ser chamado de recriação da igualdade, políticas e meios capazes de dar conta de novas realidades que impulsionam o reconhecimento e a criaçáo de novos direitos.

Antônio Augusto Cançado Trindade ensina como o meio ambiente poderá ser protegido como direito fundamental quando faz uma estreita ligação entre este e o direito ao desenvolvimento humano, também fundamental. Assim, quando pensamos no desenvolvimento sustentável, incluído está o cuidado com os limites que a própria natureza indica como constitutiva de sua sobrevivência.

José Afonso da Silva sintetiza a questão da denominação dos direitos de solidariedade, bloco no qual está inserido o direito fundamental ao meio ambiente, afirmando que:

[...] há de ser direitos de solidariedade, nunca 'direitos solidários', pois todos os direitos humanos são solidários entre si, no sentido de que se orientam harmonicamente pelo valor da dignidade da pessoa humana, enquanto a expressão 'direitos de solidariedade' se refere as novas categorias de direitos fundamentais, que como que solidariza os interesses das comunidades e dos seres humanos componentes dela. (SILVA, 2014, p. 538)

É de uma importância tão grande pensar a interligação da qualidade da vida das pessoas com a qualidade do meio ambiente sob a proteção da dignidade humana, que José Afonso da Silva reconhece:

A qualidade do meio ambiente transforma-se, assim, num bem ou patrimônio, cuja preservação, recuperação ou revitalização se tornaram um imperativo do Poder Público, para assegurar uma boa qualidade de vida, 
que implica boas condiçôes de bem-estar do homem e de seu desenvolvimento. (SILVA, 2014, p. 541)

E complementa:

A razão da tutela do meio ambiente manifesta-se no momento em que sua degradação ambiental passa a ameaçar não só o bem-estar mas qualidade de vida humana, senáo a própria sobrevivência do ser humano. (SILVA, 2014, p. 541).

Entendido o meio ambiente, então, como um novo direito fundamental de caráter vinculante à sobrevivência da pessoa humana é, portanto, obrigação do Estado respeitar, promover e cuidar do bem jurídico meio ambiente. Assim, as Constituiçóes modernas asseguram não somente o direito fundamental ao meio ambiente como reconhecem que a sua proteção garante a vida presente e futura da humanidade. E mais: os Estados determinam penalidades, ou seja, criminalizam quem o ofende e adotam políticas específicas de preservação do meio ambiente sustentável.

A propósito desse novo direito, objeto de debate e posterior reconhecimento na Declaração de Estocolmo sobre o Meio Ambiente Humano de 1972, lembra José Afonso da Silva, citando em parte a própria Declaração, que uma de suas importantes decisôes foi o reconhecimento de que,

[...] 'O homem é, a um tempo, resultado e artífice do meio que o circunda, o que lhe dá o sustento material e o brinda com a oportunidade de desenvolver-se intelectual, moral e espiritualmente. [...] Os dois aspectos do meio humano, o natural e o artificial, são essenciais para o bem-estar do homem e para que ele goze de todos os direitos humanos fundamentais, inclusive o direito à vida'. Por isso, a proteção e melhora do meio ambiente é uma questão fundamental que afeta o bem-estar dos povos e o desenvolvimento econômico do mundo inteiro; é um desejo urgente dos povos de todo o mundo e um dever de todos os governos. (SILVA, 2014, p. 541)

Tendo a qualidade da vida como centralidade do debate sobre o Direito Ambiental, afirma José Eugenio Soriano Garcia e Pedro Brufao Curiel,

Se trata este de un Derecho de la enorme amplitud del mandato de protección al que responde, en cuanto tiene por finalidad conciliar las afecciones que inevitablemente la vida moderna comporta para el medio ambiente con una adecuada calidad de vida de las generaciones presentes y futuras - haciendo realidad el logro de un desarrollo sostenible prevenir y hacer frente a las amenazas para el entorno y, cuando los daños se producen, proceder a su reparación y al restablecimiento de la funcionalidad de los recursos naturales. (GARCIA; CURIEL, 2010, p. 11) 
No contexto internacional a Declaração de Estocolmo de 1972, como visto acima, reconheceu que "[...] o homem tem o direito fundamental à liberdade, à igualdade e ao desfrute de condiçóes de vida adequada em um meio cuja qualidade lhe permite levar uma vida digna [...]” (DECLARAÇÃO DE ESTOCOLMO SOBRE O AMBIENTE HUMANO, 1972) e, mais adiante, em 1992, a Declaração do Rio sobre Meio Ambiente e Desenvolvimento, promulgada após a Conferência das Naçóes Unidas sobre Meio Ambiente e Desenvolvimento, no Rio de Janeiro, reafirmou essa necessidade e esse compromisso quando diz que "Os seres humanos estão no centro das preocupaçóes com o desenvolvimento sustentável. Têm direito a uma vida saudável e produtiva, em harmonia com a natureza" (CONFERÊNCIA DAS NAÇÓES UNIDAS SOBRE O MEIO AMBIENTE E DESENVOLVIMENTO, 1992).

Sob o contexto constitucional, Espanha e Brasil, podemos afirmar, preliminarmente, que ambos incorporam em seus textos o meio ambiente como bem jurídico a ser protegido e promovido pelo Estado. Esse tema trataremos a seguir.

\subsubsection{Contexto ccnstitucional - Brasil e Espanha}

Os direitos, do ponto de vista constitucional, para José Afonso da Silva são fundamentais,

[...] porque se trata de situaçóes jurídicas sem as quais a pessoa humana não se realiza, não convive e, ás vezes, nem mesmo sobrevive; fundamentais do 'homem' no sentido do que a todos, por igual, devem ser não apenas formalmente reconhecido, mas concreta e materialmente efetivados. (SILVA, 2014, p. 450)

Nesse sentido, aponta o autor para a interligação entre o reconhecer, constitucionalizar e efetivar em função da vida digna do ser humano. Isso requer do Estado ações concretas que levam a cabo a preservaçáo da vida e, nesse cenário sendo o meio ambiente protegido condição para a garantia da vida o constituinte assegurou que o mandato constitucional protegesse e promovesse o meio ambiente.

Por isso, reconhece Silva, citando a Declaração Universal dos Direitos do Homem que "[...] 'a proteção e melhora do meio ambiente é uma questão fundamental que afeta o bem-estar dos povos e o desenvolvimento econômico do mundo inteiro; é o desejo urgente dos povos de todo o mundo e um dever de todos os governos"' (ONU apud Silva, 2014, p. 542).

E, levando a cabo esse mandato universal, a Espanha e o Brasil incorporaram em suas constituiçóes o meio ambiente como direito fundamental à preservação da vida. $\mathrm{Na}$ Constituição espanhola, indica Fernando Simón Yarza, “[...] el derecho al medio ambiente 
del art. 45.1 CE es un auténtico derecho subjetivo, y la de quienes, además, entienden que se trata de un derecho fundamental” (YARZA, 2012, p. 73). Assim, “[...] hemos de considerar el mandato estatal de protección del medio ambiente" (YARZA, 2012, p. 90). Ademais, compreende o mesmo autor, ser a proteção do meio ambiente pressuposto básico da existência humana, portanto, consubstancial ao próprio Estado.

O texto constitucional brasileiro reconhece o meio ambiente em seu artigo 225 determinando que

Todos têm direito ao meio ambiente ecologicamente equilibrado, bem de uso comum do povo e essencial à sadia qualidade de vida, impondo-se ao Poder Público e à coletividade o dever de defendê-lo para as presentes e futuras geraçôes. (BRASIL, 1988)

Observa-se, em uma leitura sem maior esforço, que o meio ambiente na lei brasileira, da mesma forma que o entendimento constitucional espanhol, é um bem jurídico importante para a garantia da qualidade de vida das pessoas sendo, portanto, dever do Estado a sua proteção integral, direito fundamental por excelência, garantidor da dignidade humana.

A seguir, o cerne do debate nos leva à democracia como espaço de possibilidades concretas e, ao mesmo tempo, garantidor da legitimidade legislativa pelo princípio da participação, com prioridade ao entendimento de Habermas.

\section{Democracia e Participação na Cidade}

A cidade, como lugar de convivência com o outro, deve encontrar estratégias para a boa convivência. Nesse sentido, a democracia talvez faça a ponte necessária para que o cuidado, o reconhecimento e a participação social sejam elementos fundamentais na constituição da cidade. Debrucemo-nos sobre Jürgen Habermas a fim de comentarmos sobre o papel fundamental da democracia na cidade.

Habermas se insere dentro do que a tradição filosófica denominou "reviravolta linguística”, compreendida como o movimento em que

[...] a linguagem passa de objeto da reflexão filosófica para a 'esfera dos fundamentos' de todo pensar, e a filosofia da linguagem passa a poder levantar a pretensão de ser a 'filosofia primeira' à altura do nível de consciência crítica de nossos dias. (OLIVEIRA, 2001, p. 12-13)

A reflexão a partir do século XX passa a ter como base a reflexão sobre a linguagem, que pode ser vista como um "medium", pois o próprio pensamento tem como base a linguagem. 
Habermas tem a preocupação, em suas reflexóes, de ilustrar como ocorre a pretensão de entendimento entre ouvinte e falante, que o pensador alemão denominará ação comunicativa, já que a linguagem é compreendida como ação. Assim, o indivíduo que age comunicativamente busca em seus atos de fala "pretensiones universales de validez y supone que tales pretensiones pueden desempeñarse" (HABERMAS, 1997b, p. 300). O falante, com tal pretensão de validade, deve levar em consideração quatro pretensóes universais: 1) expressar-se de modo compreensível; 2) dar a entender sobre algo (apresentar algo); 3) fazer-se compreender (manifestar uma intenção); 4) entender-se com os demais (gerar uma relação interpessoal). Tais pretensóes possibilitam o entendimento, que é o "proceso de consecución de un acuerdo sobre la base presupuesta de pretensiones de validez reconocidas en común" (HABERMAS, 1997b, p. 301). Habermas denominará de Pragmática Universal o programa de investigação que busca construir a base universal de validade da fala.

O falante, que tem capacidade de comunicação, deve ter a preocupação em formular oraçóes bem elaboradas que se refiram à realidade:

- para elegir el contenido enunciativo de suerte que refleje o (cumpliendo determinadas condiciones de verdad) mencione una experiencia o un hecho (de forma que el oyente pueda compartir el saber del hablante),

- para manifestar sus intenciones de suerte que la expresión linguística reproduzca lo que el hablante tiene en mientes (de forma que el oyente pueda confiar en el hablante),

- para ejecutar el acto de habla de suerte que cumpla normas reconocidas o responda a autoimágenes aceptadas (de suerte que el oyente pueda concordar en esos valores con el hablante). (HABERMAS, 1997b, p. 328)

Ou seja, a pretensão de compreensibilidade toma o proferimento como: a) verdadeiro (representação de algo do mundo); b) veraz (expressão de algo falado); c) correto (referência às perspectivas socialmente conhecidas).

Pode-se trazer também a noção habermasiana de "linguagem ideal", em que os interlocutores têm pretensóes de entendimento que podem ser aceitas ou recusadas. Em tal situação, os falantes e ouvintes não são constrangidos por influências e coaçôes exteriores. Habermas (1997a) afirma que na "linguagem ideal" há uma exigência de simetria que pressupóe quatro requisitos de igualdade de oportunidades para todos os que participam dos atos de fala. São eles:

a) igualdade de oportunidades de todos os participantes de usarem os atos de fala, de maneira que possam sempre começar e continuar um discurso;

b) igualdade de oportunidades de todos os participantes com respeito à tematização de afirmaçóes, recomendaçóes, explicaçóes e justificaçóes, além de poderem 
criticar a validade das proposiçóes, de maneira que nenhum ditame prévio fique de fora da tematização e da crítica;

c) igualdade de oportunidades de todos os participantes no que diz respeito ao uso dos atos de fala representativos, ou seja, a possibilidade de expressarem suas atitudes, sentimentos e intenções, dado que a recíproca concordância dos agentes permite serem verazes uns com outros;

d) igualdade de chances de todos os participantes no que diz respeito ao uso dos atos de fala regulativos: ordenar, depor, permitir, proibir, por exemplo. A reciprocidade de expectativas de comportamento, com a renúncia a qualquer exclusão unilateral, garante a igualdade de chances de um falante iniciar uma ação e prosseguir com ela sem ser coagido.

Em outras palavras, a igualdade dos atores participarem do debate público, a igualdade de condiçóes para o debate, a veracidade e a não coação são os elementos da situação ideal da fala.

Com tais pressupostos, Habermas, em sua grande obra, “Teoria da Ação Comunicativa”, ilustra como o agir comunicativo, voltado para o entendimento, deve estar presente no "mundo da vida" para fazer frente à racionalidade econômica e burocrática (política) que adentraram em todas as instâncias sociais. Habermas tem a preocupação de descrever os tipos de ação que existem no "mundo da vida".

No espírito da virada pragmático-linguística, o filósofo enfatiza que a normatividade da sociedade está pautada na ação comunicativa:

Si partimos de que la especie humana se mantiene a través de las actividades socialmente coordinadas de sus miembros y de que esta coordinación tiene que establecerse por medio de la comunicación, y en los ámbitos centrales por medio de una comunicación tendente a un acuerdo, entonces la reproducción de la especie exige también el cumplimiento de las condiciones de la racionalidad inmanente a la acción comunicativa. Estas condiciones se tornan accesibles en la modernidad - es decir, con la descentración de la comprensión del mundo y la diferenciación de distintos aspectos universales de validez. (HABERMAS, 1999, p. 506)

Para ilustrar o significado da ação comunicativa, baseado em uma nomenclatura popperiana, Habermas (1999) irá distinguir outros tipos de açóes:

a) ação teleológica: orientada para uma finalidade, tem um objetivo (ação estratégica). São exemplos a economia e a sociologia;

b) ação normativa: orienta a relação em grupo, visando valores em comum. Espera-se uma obediência de todos em relação à norma;

c) ação dramatúrgica: autorrepresentação perante o público. 
Sobre a ação comunicativa, nas palavras de Habermas:

Finalmente, el concepto de acción comunicativa se refiere a la interacción de a lo menos dos sujetos capaces de lenguaje y de acción que (ya sea con medios verbales o con medios extra-verbales) entablan una relación interpersonal. Los actores buscan entenderse sobre una situación de acción para poder así coordinar de común acuerdo sus planes de acción y con ello sus acciones. El concepto aquí central, el de interpretación, se refiere primordialmente a la negociación de definiciones de la situación susceptibles de consenso. En este modelo de acción el lenguaje ocupa, como veremos, un puesto prominente. (HABERMAS, 1999, p. 124)

Com esse arcabouço, Habermas é capaz de fazer uma distinção entre a ação comunicativa e a ação estratégica. Enquanto a primeira visa o entendimento entre os interlocutores, a ação estratégica será compreendida como aquela que visa o êxito dos participantes, que tomam decisóes a partir de razóes calculistas. As três primeiras açóes explicitadas acima se encaixam na ação estratégica (HABERMAS, 1999, p. 137 e s.).

É claro que Habermas não tem a pretensão de que a ação comunicativa seja totalmente implantada na realidade, mas podemos entender tal concepção como um norte para as relaçóes sociais entre os atores capazes de comunicação.

Após explicitar a ação comunicativa, outro interessante ponto de nosso estudo diz respeito ao conceito de "mundo da vida". De forma geral, fazendo uma releitura de Edmund Husserl, Habermas compreende "mundo da vida" como o horizonte que permite os processos de entendimento, denominados ação comunicativa, além de conter a cultura, entendida como o depósito de convicçóes comuns (HABERMAS, 1992, p. 176).

Partindo das noçóes de sistema de Talcot Parsons e Niklas Luhmann, Habermas (1992, p. 176) afirmará que na modernidade a racionalidade econômica e política (com o dinheiro e o poder sendo medium) passam a ser coordenadoras de todas as açóes. Tais esferas são desconectadas do mundo da vida, que buscam, estrategicamente, um fim que náo é o entendimento. Em tais sistemas, a linguagem é uma ferramenta para atingir seus fins. No caso do sistema econômico, o consumismo e o individualismo se tornam parâmetros para as ações. Por outro lado, a instrumentalização e a burocratização tornam desconexa a política do mundo da vida.

Após tais consideraçóes, pode-se afirmar que para Habermas o Direito entra como aquilo que pode, na tentativa de superar o dinheiro e o poder como instrumentais, possibilitar a integração social. Tal objetivo caberia à ação comunicativa. Mas como essa linguagem ideal está longe de ser realizada integralmente, o Direito passa a ter um papel fundamental na sociedade:

A circulação comunicacional do mundo da vida é interrompida no ponto onde se choca com o dinheiro e o poder administrativo, meios que são 
surdos às mensagens da linguagem coloquial; pois esses códigos especiais, além de se diferenciarem da linguagem coloquial, foram desmembrados dela. É verdade que a linguagem coloquial forma um horizonte de compreensão; em princípio ela é capaz de traduzir tudo em todas as linguagens. Porém ela é incapaz de operacionalizar eficientemente para todos os destinatários suas mensagens endereçadas ao comportamento. Para traduzi-las nos códigos especiais, ela depende do direito, o qual tem o contato com o dinheiro e poder administrativo. O direito funciona como uma espécie transformadora, o qual impede, em primeiro lugar, que a rede geral da comunicaçấo, socialmente integradora, se rompa. (HABERMAS, 1997c, p. 82)

Ao falarmos em Direito, adentramos no aspecto que mais nos interessa neste artigo no que diz respeito ao pensamento habermasiano: a democracia. Habermas parte do pressuposto que o direito legítimo depende da democracia, e, assim, faz uma análise sobre o que compreende como tal regime. Nas palavras de Habermas:

A fim de obter critérios precisos para a distinção entre princípio da democracia e princípio e princípio moral, parto da circunstância de que o princípio da democracia destina-se a amarrar um procedimento de normatização legítima do direito. Ele significa, com efeito que somente podem pretender validade legítima as leis jurídicas capazes de encontrar o assentimento de todos os parceiros de direito, num processo jurídico de normatizaçáo discursiva. O princípio da democracia explica, noutros termos, o sentido performativo da prática de autodeterminação de membros do direito que se reconhecem mutuamente como membros iguais e livres de uma associação estabelecida livremente. (HABERMAS, 1997c, p. 145)

Fica mais claro o percurso até aqui. A legitimidade do Direito para Habermas depende da democracia, pois ela é o regime que permite, em um Estado laico, levar em consideração os diferentes tipos de discurso. Essa democracia é a deliberativa, na qual os cidadãos devem participar ativamente das decisóes democráticas: "o processo democrático, na medida em que satisfaz as condições de uma formação inclusiva e discursiva da opinião e da vontade, justifica uma presunção de aceitabilidade racional dos resultados" (HABERMAS; RATZINGER, 2007, p. 29).

O Estado Democrático de Direito permite, em sua constituição, a participação ativa dos seus cidadãos. Mas também é possível que um indivíduo nada tenha a contribuir para o processo democrático, sendo apenas um destinatário do Direito. É uma escolha individual:

De destinatários do direito espera-se apenas que, no exercício de suas liberdades (e pretensôes) subjetivas, não ultrapassem os limites legais. Deles se exige que obedeçam às leis obrigatórias da liberdade, mas de 
cidadãos que exercem o papel de colegisladores democráticos, espera-se outro tipo de motivação e atitude. (HABERMAS; RATZINGER, 2007, p. 33-34)

Com tais consideraçóes, é possível defender a democracia como sendo o regime propício para a participação social, que é fundamental no reconhecimento, na promoção e no respeito ao meio ambiente urbano.

\subsection{Proteger e Promover o Direito Fundamental ao Meio Ambiente: A Participa- ção Social}

Sendo o meio ambiente um direito fundamental implícito na qualidade da vida humana, cerne do Estado Democrático de Direito e, portanto, recepcionado pelas constituiçóes modernas, nomeadamente a brasileira e a espanhola, o passo seguinte não poderia ser outro que não os princípios da proteção e da promoção do meio ambiente saudável em que a Dignidade ganha centralidade. Isso nos conduz à garantia do espaço da participação como especificidade de legitimação pública das iniciativas em prol do meio ambiente saudável e seguro para as geraçóes.

Sobre o tema da proteção jurídica dos direitos fundamentais, fala Yarza sobre a importância da

[...] relevancia de la conexión entre medio ambiente y los llamados deberes de protección que no solo as intervenciones en los derechos fundamentales, sino también los 'peligros' para estos derechos, pueden dar lugar a abrogaciones positivas [...]. (YARZA, 2012, p. 102-103)

Tal constatação, nesse contexto, gera a obrigação estatal na promoção de iniciativas projetivas em prol do meio ambiente.

O meio ambiente, no contexto brasileiro, assegurado pelo artigo 225 da Constituição, adverte José Afonso da Silva que “[...] integra, na sua complexidade, a disciplina urbanista, mas se revela como social, na medida em que sua concreção importa em prestação do Poder Público" (SILVA, 2015, p. 320).

E, sobre a importância da participação nos termos da democracia descrita acima que delineá-la no processo de construção e de efetivação do direito fundamental ao meio ambiente, adverte Miguel Angel Sanches Ramos:

El tema de la participación ciudadana esta bastante ligado con la democratización como proceso de apertura de estructura y instituciones para acercar y organizar una relación entre gobierno y gobernados más directa y funcional. (RAMOS, 2009, p. 86) 
O termo participação, utilizado por Ramos, citando Nohlen (2006), recebe a importância do tomar parte, congregar diferenças, organização das pessoas que guardam motivos comuns. Participar e intervir nos assuntos que podemos e devemos decidir, imprimindo o interesse individual no processo de formação e de governabilidade democrática.

Assim define Ramos: "Por participación ciudadana se entente aquel proceso por el cual los sujetos, a título individual o colectivo, desarrollan una acción tendiente a vincular una experiencia o una opinión con los ámbitos publico o político” (RAMOS, 2009, p. 91).

Por fim, para efetivar direitos fundamentais necessário se faz pensar, dentro do processo democrático, a importância da participação cidadã e, mais, entendê-la como condição de legitimidade das decisóes e iniciativas públicas em defesa da vida que passa pelo reconhecimento do meio ambiente como direito fundamental.

\section{Conclusões}

O presente texto explicitou, em primeiro lugar, a ideia do enquadramento do meio ambiente como direito fundamental e, nesse sentido, a maioria dos autores justificam a inclusão do meio ambiente no rol dos direitos fundamentais pautado na ideia da primazia da vida, cerne unificador das constituiçóes cujo o princípio basilar é a dignidade humana.

Assim, mesmo que o texto Constitucional não o consagre como fundamental, como é o caso da Constituição Espanhola, o fundamento basilar da necessidade de preservar e proteger o meio ambiente se funda na dignidade humana e, portanto, na centralidade da vida.

Por isso, Direitos humanos, no presente trabalho são entendidos como aqueles intrínsecos às pessoas humanas, protegidos pelas constituições e ilustrados por muitos documentos internacionais e direitos fundamentais os reconhecidos pelo texto constitucional com fundamento precípuo na dignidade humana, na defesa da vida.

Nesse sentido, a democracia, no presente texto, se apresenta como ponte necessária para que o cuidado, o reconhecimento e a participaçáo social sejam elementos fundamentais na preservação da vida. Assim, com Jürgen Habermas, buscou-se pensar o papel fundamental da democracia para a garantia da participaçáo social em defesa da vida que tem como condição a preservação do meio ambiente em sua conexão com a garantia constitucional da vida digna e adequada.

Por último, em defesa da importância da participação democrática, o texto buscou delineá-la, no processo de construção e de efetivação do direito fundamental ao meio ambiente, nos moldes que nos adverte Miguel Angel Sanches Ramos em que o tema da participação requer a democratização e abertura de estruturas e instituiçóes, como forma de garantia do reconhecimento e da proteçáo do direito fundamental ao meio ambiente. 
Assim, o meio ambiente se constitui em um direito fundamental implícito na qualidade da vida humana, cerne do Estado Democrático de Direito, recepcionado pelas constituiçôes modernas, cujos princípios da proteção e da promoção do meio ambiente saudável garantirão à dignidade humana a centralidade da proteção da vida saudável e segura para as geraçóes.

\section{Referências}

BRASIL. Constituição da República Federativa do Brasil. 49a ed. São Paulo: Saraiva, 2014.

BRASIL. Constituiçáo da República Federativa do Brasil de 1988. Disponível em: <http://www.planalto.gov.br/ccivil_03/constituicao/constituicaocompilado.htmederal>. Acesso em: 15 mar. 2015.

BARROSO, Luis Roberto. Curso de Direito Constitucional contemporâneo - Os Conceitos Fundamentais e a Constituição do Novo Modelo. 5a ed. São Paulo: Saraiva, 2015.

CANOTILHO, José Joaquim Gomes. Direito Constitucional. $7^{\text {a }}$ ed. Coimbra: Almedina, 2003.

CARVALHO, Edson Fereira de. Meio Ambiente e Direitos Humanos. 2a ed. Curitiba: Juruá, 2011.

CARVALHO, Newton Teixeira; RIOS, Mariza. Copa do mundo, olimpíadas e estado de exceção - Uma constante e permanente negativa de direitos fundamentais, inclusive com a suspensão de nosso ordenamento jurídico em prol da soberania Fifa. In: CARVALHO, Newton Teixeira; REIS, Émilien Vilas Boas (Coord.). Cidade, Eventos Esportivos e Estado de Exceçáo. Belo Horizonte: Del Rey, 2014.

CONFERÊNCIA DAS NAÇÓES UNIDAS SOBRE O MEIO AMBIENTE E DESENVOLVIMENTO, 1992 - ECO-92 ou RIO-92. Disponível em: <http://www. direitoshumanos.usp.br/index.php/Agenda-21/capitulo-01-conferencia-das-nacoes-unidas-sobre-o-meio-ambiente-e-desenvolvimento.html>. Acesso em: 28 abr. 2015.

DECLARAÇÃO DE ESTOCOLMO SOBRE O AMBIENTE HUMANO, 1972. Disponível em: <http://www.direitoshumanos.usp.br/index.php/Meio-Ambiente/ declaracao-de-estocolmo-sobre-o-ambiente-humano.html>. Acesso em: 28 abr. 2015

DECLARAÇÃO DO RIO SOBRE MEIO AMBIENTE E DESENVOLVIMENTO. Disponível em: <http://www.onu.org.br/rio20/img/2012/01/rio92.pdf>. Acesso em: 28 abr. 2015. 
DECLARAÇÃO UNIVERSAL DOS DIREITOS HUMANOS, 1948. Disponível em: <http://unesdoc.unesco.org/images/0013/001394/139423por.pdf>. Acesso em: 28 abr. 2015.

DERANI, Cristiane. Direito ambiental econômico. São Paulo: Max Limonad, 1997.

GARCIA, José Eugenio Soriano; CURIEL, Pedro Brufao. Claves de Derecho Ambiental I. Madrid: Iustel, 2010.

HABERMAS, Jürgen. Teoría de la acción comunicativa II: Crítica de la razón funcionalista. Trad. Manuel Jiménez Redondo. Madrid: Taurus, 1992.

. Teorías de la verdad. In: HABERMAS, Jürgen. Teoría de la acción comunicativa: complementos y estudios previos. Trad. Manuel Jiménez Redondo. Madrid: Catedras, 1997a, p. 113-158.

- ¿Qué significa pragmática universal? In: HABERMAS, Jürgen. Teoría de la acción comunicativa: complementos y estudios previos. Trad. Manuel Jiménez Redondo. Madrid: Catedras, 1997b, p. 299-368.

. Direito e democracia: entre facticidade e validade. v. 1. Trad. Flávio Beno Siebeneichler. Rio de Janeiro: Tempo Brasileiro, 1997c.

. Teoría de la acción comunicativa I: Racionalidad de la acción y racionalización social. Trad. Manuel Jiménez Redondo. Madrid: Taurus, 1999.

; RATZINGER, Joseph. Dialética da secularização. Trad. Alfred J. Keller. Aparecida: Ideias e Letras, 2007.

HERRERO, Francisco Javier. O “ethos" atual e a ética. Síntese Rev. de Filosofia. Belo Horizonte, vol. 31, n. 100, 2004, p. 149-161.

KAUFMANN, Matthias. Em defesa dos direitos humanos: consideraçóes históricas e de princípio. Trad. Rainer Patriota. São Leopoldo: Unisinos, 2013.

LASSALlE, Ferdinand. A essência da Constituiçăo. Rio de Janeiro: Lumen Juris, 2001.

MAC DOWELL, João Augusto. Ética e Direito no pensamento da Henrique de Lima Vaz. Revista Brasileira de Direito Constitucional - RBDC, n. 09, jan./jun. 2007, p. 237-273.

OLIVEIRA, Manfredo Araújo de. Reviravolta linguístico-pragmática. São Paulo: Loyola, 2001.

ORGANIZAÇÃO DAS NAÇÕES UNIDAS (ONU). Declaraçáo de Estocolmo sobre Meio Ambiente Humano de 1972. Disponível em: <www.mma.gov.br/estruturas/agenda21/_arquivos/estocolmo.doc > Acesso em: 19 jan. 2015.

ORDINE, Nuccio. La utilidad de lo inútil. Traducción de Jordi Bayod. Barcelona: Acantilado, 2013. 
PEREIRA, Jane Reis Gonçalves. Interpretaçáo constitucional e direitos fundamentais: uma contribuição ao estudo das restriçốes aos direitos fundamentais na perspectiva da teoria dos princípios. Rio de Janeiro: Renovar, 2006.

PIOVESAN, Flávia C. Direitos humanos e o direito constitucional. São Paulo: Saraiva, 2006.

RAMOS, Miguel Angel Sanches. La participacíon ciudadana em la esfera de lo publico. Red de Revistas Científicas de América Latina y el Caribe, España y Portugal. Disponível em: <www.redalyc.org>. Acesso em: 20 mar. 2015.

SILVA, José Afonso da. Teoria do Conhecimento Constitucional. São Paulo: Malheiros, 2014.

Curso de Direito Constitucional Positivo. 38ª ed. Sáo Paulo: Malheiros, 2015.

TIMM, Ricardo. A dignidade humana desde uma antropologia dos intervalos - uma síntese. Veritas. Porto Alegre, vol. 53, n. 2, abr-jun. 2008, p. 120-149.

TRINDADE, Antônio Augusto Cançado. Meio Ambiente e Desenvolvimento: formulação, natureza jurídica e implementação do direito ao desenvolvimento como um direito humano. Revista da Procuradoria-Geral do Estado do Ceará. Fortaleza, v. 9, n. 11, p. 11-42, 1992.

VICHI, Bruno de Souza. Política Urbana - Sentido jurídico, competência e responsabilidades. Belo Horizonte: Fórum, 2007.

YARZA, Fernando Simón. Medio Ambiente y derechos fundamentales. Madrid: Centro de Estudos Politicos Constitucionais, 2012. 